\title{
Stabilization of milk proteins in acidic conditions by pectic polysaccharides extracted from soy flour
}

\author{
Y. Cai, B. Cai, and S. Ikeda ${ }^{1}$ \\ Department of Food Science, University of Wisconsin, Madison 53706
}

\section{ABSTRACT}

Pectic polysaccharides were extracted from soy flour at either room temperature (SPRT) or $121^{\circ} \mathrm{C}(\mathrm{SPH})$, and their abilities to stabilize milk proteins in acidic conditions were evaluated. Both SPRT and SPH were found to contain proteinaceous components that were difficult to dissociate from polysaccharide components using size exclusion chromatography, whereas the molar mass of the former was approximately twice that of the latter. Due to the higher molar mass, SPRT was expected to provide stronger steric effects to prevent aggregation between milk proteins in acidic conditions than SPH. Alkaline treatment of SPRT for breaking $O$-linkages between AA and monosaccharide residues decreased its molar mass by approximately $160 \mathrm{kDa}$, indicating that they contained naturally occurring conjugates of pectic and proteinaceous moieties. Particle size distributions in simulated acidified milk drink samples containing $0.2 \%$ SPRT or SPH showed monomodal distributions with median diameters of around $1.2 \mu \mathrm{m}$ at $\mathrm{pH}$ 4. The presence of large protein aggregates $(\sim 5$ $\mu \mathrm{m})$ was detected at $0.2 \%$ SPRT and $\mathrm{pH} 3.2,0.6$ to $0.8 \%$ SPRT and $\mathrm{pH} 4$, or $0.2 \% \mathrm{SPH}$ and $\mathrm{pH}$ 3.4. The presence of excess polysaccharide molecules unbound to proteins was detected at $0.2 \%$ SPRT and $\mathrm{pH} 3.2$ to 3.4, 0.4 to $0.8 \%$ SPRT and $\mathrm{pH} 4,0.2 \% \mathrm{SPH}$ and $\mathrm{pH} 3.4$ to 3.6 , and 0.4 to $0.8 \% \mathrm{SPH}$ and $\mathrm{pH} 4$. The present results suggest that molecular characteristics of pectic polysaccharides vary depending on extraction conditions and hence their functional behavior.

Key words: acidified milk, stability, casein micelle, pectin

\section{INTRODUCTION}

Acidified milk drinks (AMD) are milk-based beverage products with a rising market interest because of physiological benefits of milk proteins (Corbo et al.,

Received October 21, 2016.

Accepted May 29, 2017.

${ }^{1}$ Corresponding author: shinya.ikeda@wisc.edu
2014). They are prepared by directly adding acids or fruit juice as acidulants to milk or fermenting milk using lactic acid bacteria (Liu et al., 2006). Prior to acidification, CN micelles in milk are stabilized through electrostatic repulsions between net-negatively charged $\mathrm{CN}$ micelles and steric hindrance arising from hairy layers of $\kappa-\mathrm{CN}$, whose molecular chain is negatively charged and thus extends into the aqueous phase from the net-negatively charged micelle surface (Dalgleish, 1998; De Kruif and Tuinier, 2001; Philippe et al., 2005). As pH decreases, however, CN micelles lose net charges, leading to losses of intermicellar electrostatic repulsions and steric hindrance against aggregation between $\mathrm{CN}$ micelles due to the collapse of the $\kappa-\mathrm{CN}$ hairy layer surrounding them. It is therefore a common practice in the food industry to add functional hydrocolloids, such as anionic polysaccharide including high methoxyl pectin (Laurent and Boulenguer, 2003) and carboxymethyl cellulose (Ntazinda et al., 2014), to acidified milk beverage products as stabilizers to prevent excessive aggregation of milk proteins.

High-methoxyl pectin extracted from citrus peel or apple pomace is the most commonly used stabilizer for AMD (Pereyra et al., 1997; Jensen et al., 2010). Pectin is a generic name for a group of water-soluble cell wall polysaccharides varying in the chemical structure and typically comprises a relatively long backbone of rhamnogalacturonan and short branches of neutral sugars (Caffall and Mohnen, 2009; Sila et al., 2009). In AMD, negatively charged carboxyl groups on the backbone of pectin are considered to bind electrostatically to positively charged groups of CN micelles, whereas unbound parts of the pectin backbone form loops and tails that protrude into the aqueous phase and provide steric hindrance against aggregation between $\mathrm{CN}$ micelles (Tromp et al., 2004; Sejersen et al., 2007; Jensen et al., 2010). Adding pectin thus compensates for the collapse of hairy layers of $\kappa-\mathrm{CN}$ on $\mathrm{CN}$ micelle surfaces during acidification and prevents the destabilization of CN micelles, leading to the formation of large aggregates and even precipitates in AMD.

Pectic polysaccharide extracted from soybeans at elevated temperatures after removal of oil and protein is a recent addition to functional stabilizers for milk 
proteins in acidic conditions and is termed soybean soluble polysaccharide (SSPS; Nakamura et al., 2003, 2006b, 2014). Soybean soluble polysaccharide comprises $49.7 \%$-mol galactose, $19.8 \%$-mol galacturonic acid, 18.5\%-mol arabinose, 5.1\%-mol rhamnose, $2.9 \%$ mol xylose, 2.0\%-mol glucose, and 2.0\%-mol fructose and consists of a backbone containing rhamnogalacturonan I regions and homogalacturonan regions and relatively long side chains of neutral sugars such as galactan and arabinan in the rhamnogalacturonan I regions (Nakamura et al., 2001, 2002). The presence of long side chains makes SSPS a compact molecule, the overall dimension of which has been evaluated to be approximately $100 \mathrm{~nm}$, enabling the stabilization of milk proteins without causing undesired increases in thickness or viscosity (Ikeda et al., 2005; Nakamura et al., 2012; Chivero et al., 2014). Another unique feature of SSPS is that it contains a small fraction $(\sim 5-14 \%)$ of proteinaceous components that appear to be covalently linked to polysaccharide moieties (Matsumura et al., 2003; Nakamura et al., 2004b). Therefore, SSPS possesses emulsifying abilities (Nakamura et al., 2004a,b, 2006a), whereas the effect of the proteinaceous moiety on the stabilization of milk proteins has hardly been investigated.

The production of pectin stabilizers typically involves heating an aqueous suspension of raw materials in acidic conditions. Faravash and Ashtiani (2007) investigated the yield of pectin from peach pomace as a function of extraction temperature and found that the yield increased as the temperature increased from 40 to $120^{\circ} \mathrm{C}$ at a certain $\mathrm{pH}$ between 1.2 and 2.5 and a heating duration of between 10 and $80 \mathrm{~min}$. However, heating in an acidic condition promotes hydrolysis, leading to shortening of backbones and side chains (Kirby et al., 2006). Heating an aqueous dispersion containing both protein and polysaccharide may also induce Maillard reactions, the initial stage of which includes the formation of covalent linkages between nucleophilic amine groups of protein and reducing ends of polysaccharide (Zhu et al., 2008). The objectives of this study were (1) to extract pectic polysaccharides (hereafter referred to as soybean pectin) from soy flour using conditions for manufacturing SSPS and conditions that do not involve heating during extraction and (2) to evaluate soybean pectins' abilities to stabilize milk proteins in acidic conditions.

\section{MATERIALS AND METHODS}

\section{Materials}

Defatted soy flour containing $32 \%$ carbohydrate, $53 \%$ protein, and $3 \%$ fat (percent symbols were used as units of weight per weight concentration throughout this study) was donated by Archer Daniels Midland Co. (Decatur, IL). Nonfat dry milk containing $35.9 \%$ protein was donated by Agropur Ingredients (La Crosse, WI). Carbazole was purchased from Sigma-Aldrich Chemical Ltd. (St. Louis, MO). All other analyticalgrade reagents were purchased from Fisher Scientific Co. (Pittsburgh, PA).

\section{Preparation of Soybean Pectin}

The method of pectin extraction at an elevated temperature was adopted from that of SSPS (Nakamura et al., 2001). Defatted soy flour was suspended in 5 volumes of hexane heated to $40^{\circ} \mathrm{C}$ for $1 \mathrm{~h}$ to remove remaining lipids (Nakamura et al., 2001). Hexane is used as a solvent in conventional vegetable oil manufacturing (Tres et al., 2014). Residual materials were then suspended twice in 11 volumes of water heated to $50^{\circ} \mathrm{C}$ for $1 \mathrm{~h}$ to remove proteins and other water-soluble components. Insoluble materials were collected, suspended in distilled water, adjusted to $\mathrm{pH} 4.5$ using citric acid, and heated at $121^{\circ} \mathrm{C}$ for $2 \mathrm{~h}$ in an autoclave. Insoluble materials were removed using a centrifuge (Beckman, Brea, CA) at $7,000 \times g$ for $30 \mathrm{~min}$. The supernatant was dialyzed overnight against deionized water through 3.5-kDa molar mass cutoff dialysis tubing (Pierce Biotechnology, Rockford, IL) and freeze dried (Labconco, Kansas City, MO).

The method of pectin extraction at room temperature was derived from that of sugar beet pectin (Kirby et al., 2006). Defatted soy flour was suspended twice in 4 volumes of phenol-saturated Tris buffer $(\mathrm{pH} 8)$ to remove remaining proteins. Insoluble materials were then suspended 3 times in water, collected before being adjusted to $\mathrm{pH} 6.0$ using acetic acid, and incubated at room temperature for $48 \mathrm{~h}$ with moderate stirring. Precipitates were recovered using a centrifuge; washed twice in 4 volumes of water; incubated overnight at room temperature in an aqueous solution containing $100 \mathrm{mM} \mathrm{NaCl}$ for adjusting the ionic strength, $50 \mathrm{mM}$ sodium acetate for providing buffering capacity, and $0.02 \%$ sodium azide for preventing bacterial growth; and adjusted to $\mathrm{pH}$ 4.5. To extract pectic polysaccharides, the recovered precipitate was suspended in 11 volumes of $\mathrm{HCl}$ solution of $\mathrm{pH} 1.5$ and incubated at room temperature for $1 \mathrm{~h}$. Sodium acetate $(10 \mathrm{mM})$ was added to the recovered supernatant to adjust to approximately $\mathrm{pH} 3$, and then $\mathrm{NaOH}$ was added to adjust to $\mathrm{pH} 4.5$ (Kirby et al., 2006). The solution was dialyzed overnight against deionized water through 3.5$\mathrm{kDa}$ molar mass cutoff dialysis tubing (Pierce Biotechnology) and freeze dried (Labconco, Kansas City, MO). 
Part of the pectin samples extracted at room temperature was subjected to alkaline treatment in the presence of excess reducing agent to break $O$-glycosidic linkages between serine or threonine residues and monosaccharide residues but not to isomerize or degrade pectin molecules (Akiyama et al., 1984; Patel et al., 1993). Pectin samples were dissolved in aqueous solutions containing $0.25 \mathrm{M} \mathrm{NaOH}$ and $0.25 \mathrm{M} \mathrm{NaBH}_{4}$ to give a concentration of $5 \mathrm{mg} / \mathrm{mL}$, incubated at $50^{\circ} \mathrm{C}$ for $5 \mathrm{~h}$, dialyzed overnight against deionized water through 3.5-kDa molar mass cutoff dialysis tubing (Pierce Biotechnology), and freeze dried (Labconco, Kansas City, $\mathrm{MO})$.

\section{Chemical Composition Analysis}

Galacturonic acid content was determined using a colorimetric method using carbazole and sulfuric acid (Taylor, 1993). Protein content was determined using a bicinchoninic acid protein assay kit (Pierce Biotechnology). Measurements were done in triplicate to report means and standard deviations.

\section{Particle Size Distribution and Zeta Potential Measurements}

Particle size distribution and zeta potential were measured at room temperature using a Zetasizer NanoZS (Malvern Instruments Ltd., Malvern, UK). The instruments measure diffusion coefficients of particles moving in Brownian motion to calculate particle size distributions based on the Stokes-Einstein relationship as well as electrophoretic mobilities of particles in an electric field to calculate zeta potentials. For particle size distribution measurements, pectin samples were dissolved in deionized water to give a concentration of $0.01 \%$. Measurements were repeated 6 times and averaged. A relative refractive index $(\mathbf{R I})$ value of particles of 0.01 and an RI of dispersant of 1.56 were used for calculation of volume-based particle size distributions. For zeta potential measurements, pectin samples were dissolved in deionized water to give a concentration of $0.1 \%$ and diluted to $0.01 \%$ using $5 \mathrm{~m} M$ sodium citrate buffer ( $\mathrm{pH} 3-5)$ or $5 \mathrm{~m} M$ sodium phosphate buffer $(\mathrm{pH}$ 6-7). The zeta potential of each sample was measured 5 times at room temperature and averaged.

\section{Size Exclusion Chromatography-Multiangle Laser Light Scattering Analysis}

The size exclusion chromatography-multiangle laser light scattering (MALLS) system consisted of Superose 6HR 10/30 and Superose 12HR 10/30 columns (Amersham Pharmacia Biotech AB, Uppsala, Sweden) connected in series, a UV absorbance detector (GBC Scientific Equipment Ltd., Braeside, Australia) operating at $280 \mathrm{~nm}$, a differential RI detector (model 2414, Waters, Milford, MA), and a Dawn DSP MALLS detector (Wyatt Technology, Santa Barbara, CA) equipped with a helium-neon laser $(632.8 \mathrm{~nm})$ and a K-5 flow cell. Pectin samples were dissolved in elution buffer containing $20 \mathrm{~m} M$ imidazole, $50 \mathrm{~m} M \mathrm{NaCl}$, and $0.1 \%$ $\mathrm{NaN}_{3}$ to give a concentration of $0.5 \%$ and were adjusted to $\mathrm{pH}$ 7.0. Sample solutions were filtered through 0.22$\mu \mathrm{m}$ syringe filters (Sigma-Aldrich Chemical Ltd.) before injection into the system and eluted at a flow rate of $0.5 \mathrm{~mL} / \mathrm{min}$. Molar masses were calculated using a first-order Debye fit, a specific RI increment $(\mathrm{d} n / \mathrm{d} c)$ value of $0.154 \mathrm{~mL} / \mathrm{g}$, and a second virial coefficient $\left(\mathrm{A}_{2}\right)$ of zero. Elution profiles were analyzed using Astra software version 4.0 (Wyatt Technology).

\section{Preparation of Simulated AMD}

Nonfat dry milk was reconstituted to a $17 \%$ solution containing $0.04 \%$ sodium azide for preventing bacterial growth and heated first at $60^{\circ} \mathrm{C}$ for $2 \mathrm{~h}$ to fully hydrate milk solids and then at $80^{\circ} \mathrm{C}$ for 15 min to simulate pasteurization. Pectin solutions were prepared separately by stirring $2 \%$ dispersions in deionized water at room temperature for $2 \mathrm{~h}$ followed by heating at $70^{\circ} \mathrm{C}$ for $30 \mathrm{~min}$ to ensure full hydration. The reconstituted milk, pectin solution, deionized water, and glucono $\delta$-lactone were mixed at prespecified ratios to give a final milk solid content of $8.5 \%$, corresponding to a protein content of $3.0 \%$, pectin content of 0.2 to $0.8 \%$, and glucono $\delta$-lactone concentration of 1.5 to $2.0 \%$ and were incubated at $20^{\circ} \mathrm{C}$ for $24 \mathrm{~h}$. Samples were adjusted to $\mathrm{pH} 3.2$ to 4 using $5 \mathrm{M} \mathrm{HCl}$, passed twice through a high-pressure homogenizer (Avestin, Ottawa, ON, Canada) operating at $40 \mathrm{MPa}$, and stored at $4^{\circ} \mathrm{C}$ for 24 $\mathrm{h}$ before evaluation. The AMD samples were prepared in triplicate at each combination of pectin concentration and $\mathrm{pH}$.

\section{Evaluation of Simulated AMD}

The AMD samples were diluted to a milk solid concentration of $0.01 \%$ and prespecified $\mathrm{pH}$ using $5 \mathrm{mM}$ sodium citrate buffer. Particle size distribution and zeta potential were measured at room temperature using a Zetasizer Nano-ZS as described previously.

\section{Statistical Analysis}

One-way ANOVA was performed using JMP statistical software (JMP Pro 10.0, SAS Institute, Cary, NC). 
Table 1. Chemical composition (mean $\pm \mathrm{SD} ; \mathrm{n}=3$ ) and yield of pectic polysaccharide extracted using different conditions

\begin{tabular}{|c|c|c|c|}
\hline \multirow[b]{2}{*}{ Sample } & \multicolumn{2}{|c|}{ Content (\%) } & \multirow[b]{2}{*}{ Yield $(\%)$} \\
\hline & Protein & Galacturonic acid & \\
\hline Soybean pectin extracted at $121^{\circ} \mathrm{C}$ & $8.59 \pm 0.13^{\mathrm{a}}$ & $18.07 \pm 0.85^{\mathrm{a}}$ & 3.40 \\
\hline Soybean pectin extracted at room temperature & $6.50 \pm 0.13^{\mathrm{b}}$ & $15.84 \pm 0.72^{\mathrm{a}}$ & 1.11 \\
\hline
\end{tabular}

${ }^{\mathrm{a}, \mathrm{b}}$ Different superscripts in a column indicate significant differences $(P<0.05)$.

Differences were considered to be significant at $P<$ 0.05 .

\section{RESULTS AND DISCUSSION}

\section{Molecular Characterization of Soybean Pectin}

Table 1 shows the chemical composition and percentage yield of the soybean pectin extracted at either $121^{\circ} \mathrm{C}$ (SPH) or room temperature (SPRT). Heating during extraction led to a higher yield of $3.40 \%$, more than 3 times the yield of extraction at room temperature. These results were consistent with the effect of extraction temperature on the yield of pectin reported in the literature (Faravash and Ashtiani, 2007). The SPH also had a significantly higher protein content than the SPRT $(P<0.05)$, whereas galacturonic acid contents were not significantly different $(P=0.06)$.

Figure 1 shows volume-based particle size distributions of pectin samples extracted at the 2 different temperatures. The SPH showed 2 main peaks with mean diameter of 16 and $28 \mathrm{~nm}$, whereas the SPRT had a major peak at $38 \mathrm{~nm}$ and a broad distribution extending beyond $100 \mathrm{~nm}$ with a minor peak around $250 \mathrm{~nm}$. These results suggest that heating during extraction

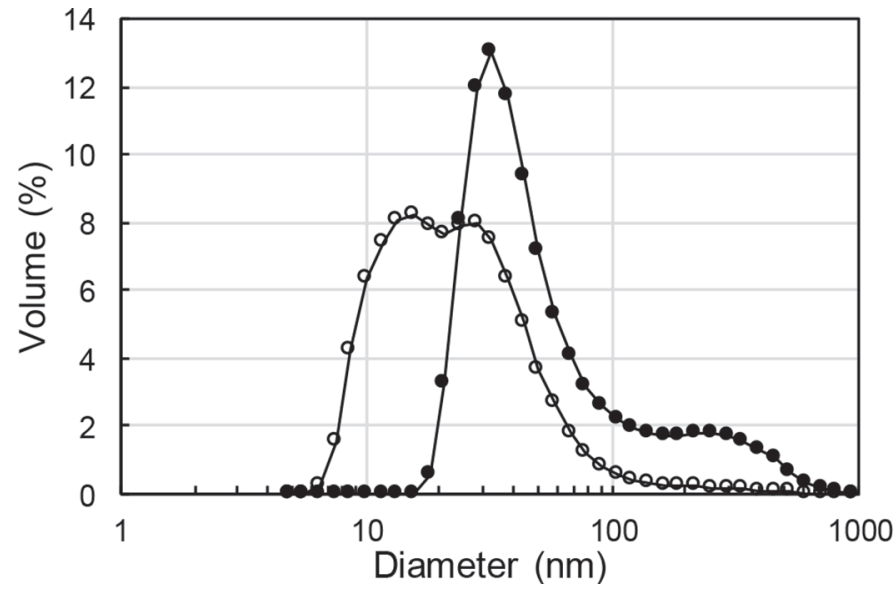

Figure 1. Volume-based particle size distributions in $0.01 \%$ aqueous solutions of soybean pectin extracted at $121^{\circ} \mathrm{C}$ (open circles) or at room temperature (solid circles). causes a more enhanced degradation of pectin molecules. The larger molecular size of SPRT is considered to be advantageous in protein stabilization because it is expected to lead to a greater surface load and stronger steric hindrance, as has been observed previously in studies using polymerized SSPS (Nakamura et al., 2012).

In Figure 2, zeta potential values of pectin samples extracted at the 2 different temperatures are plotted as a function of $\mathrm{pH}$. The zeta potential of $\mathrm{SPH}$ decreased from -6.5 to $-24.7 \mathrm{mV}$ with increasing $\mathrm{pH}$ from 3 to 7 , and that of SPRT decreased from -4.1 to $-27.9 \mathrm{mV}$. The $\mathrm{SPH}$ were more negatively charged than the SPRT at $\mathrm{pH} 3$ to $5(P<0.05)$, whereas an opposite trend was observed at $\mathrm{pH} 7$. The $\mathrm{SPH}$ had a slightly higher galacturonic acid content even though the difference was not statistically significant (Table 1). Typically, AMD products are adjusted to $\mathrm{pH} 3.2$ to 4.2 for the sake of protein stability (Laurent and Boulenguer, 2003; Sejersen et al., 2007; Ntazinda et al., 2014). Therefore, the present results imply that SPH may bind to CN micelles more readily than SPRT in AMD, in which milk proteins are net-positively charged. If the $\mathrm{pH}$-dependent charge profiles are solely attributable to galacturonic acid groups, charge profiles of SPRT and $\mathrm{SPH}$ should be in parallel to each other in the entire $\mathrm{pH}$ range examined. Therefore, the crossover between the zeta potential profiles of SPH and SPRT around $\mathrm{pH} 6$ indicates that proteinaceous components in these samples (Table 1) also contribute to overall charge profiles. It is also likely that their AA compositions are dependent on the temperature of extraction.

Figure 3 shows size exclusion chromatographyMALLS elution profiles of SPH, SPRT, and SPRT treated with alkali. All these samples showed the most intense RI peaks around an elution volume of $16 \mathrm{~mL}$, representing high molecular weight polysaccharide fractions. The molar masses of these peaks were calculated to be 966 and $1,830 \mathrm{~kg} / \mathrm{mol}$ for $\mathrm{SPH}$ and SPRT, respectively. The difference in the molar mass confirms that native structures of pectin in the cell wall are better preserved during extraction at room temperature. The SPH showed an additional shoulder around an elution volume of $18 \mathrm{~mL}$ and a molar mass of $277 \mathrm{~kg} / \mathrm{mol}$, 


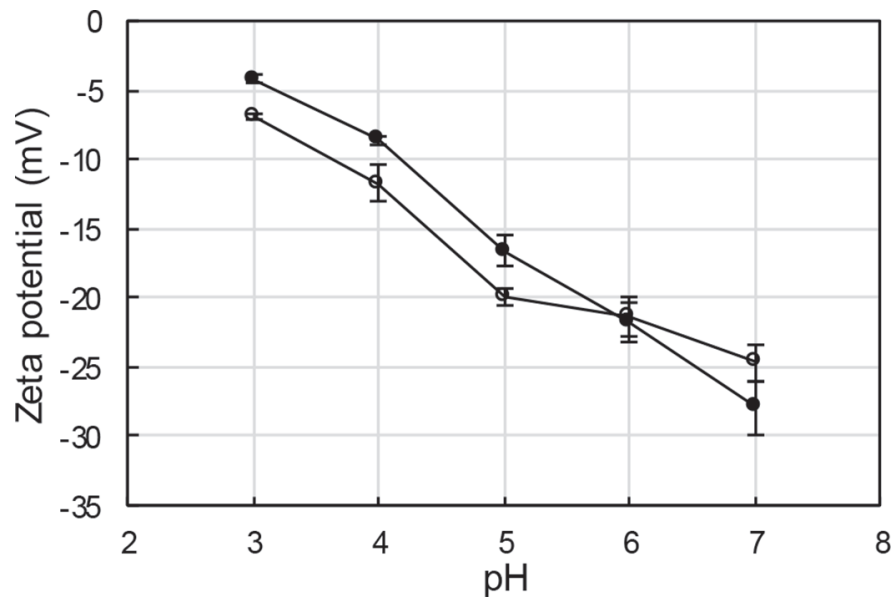

Figure 2. Zeta potentials of $0.01 \%$ aqueous solutions of soybean pectin extracted at $121^{\circ} \mathrm{C}$ (open circles) or at room temperature (solid circles). Error bars indicate standard deviation.

indicating its wider molar mass distribution compared with the SPRT. These results are most likely to be attributed to heat-induced degradation during extraction. Minor RI peaks around $37 \mathrm{~mL}$ and UV peaks around 36 $\mathrm{mL}$ likely represent relatively small polysaccharide and polypeptide components, respectively.

In Figure 3, both SPH and SPRT show UV peaks in the same elution volume range as that of the major RI peaks, indicating the presence of proteinaceous components. In contrast, the SPRT treated with alkali showed the most intense RI peak around an elution volume of $16 \mathrm{~mL}$ but no shoulder and UV peak (Figure 3c). The absence of a shoulder in RI profiles before and after the alkaline treatment indicates that the treatment did not disrupt carbohydrate moieties significantly. Furthermore, the molar mass of the alkali-treated SPRT was calculated to be $1,670 \mathrm{~kg} / \mathrm{mol}$, which is $160 \mathrm{~kg} / \mathrm{mol}$ less than that of SPRT. This reduction in molar mass suggests that SPRT contains protein moieties, the molar mass of which is $160 \mathrm{~kg} / \mathrm{mol}$, and that those protein moieties are covalently bonded to pectin moieties, the molar mass of which is $1,670 \mathrm{~kg} / \mathrm{mol}$, via $O$-glycosidic linkages. It is worth noting that alkaline treatments were performed in the presence of excess reducing agent to prevent isomerization and degradation of pectin moieties (Patel et al., 1993), and hence reducing ends of pectin were most likely to be converted to alcohol groups, leading to a marginal increase in molar mass by $1 \mathrm{~g} / \mathrm{mol}$. Therefore, it is highly likely that soybean pectin contains naturally occurring conjugates of pectin and protein components. Nakamura et al. (2004b) digested pectin molecules in SSPS using pectinase and determined the molecular weight of the protein moiety to be $50 \mathrm{kDa}$ based on electrophoretic analysis. The remarkably greater molar mass of the protein moiety of SPRT implies that the extraction of pectin at elevated temperatures causes the degradation of not only pectin moieties but also protein moieties.
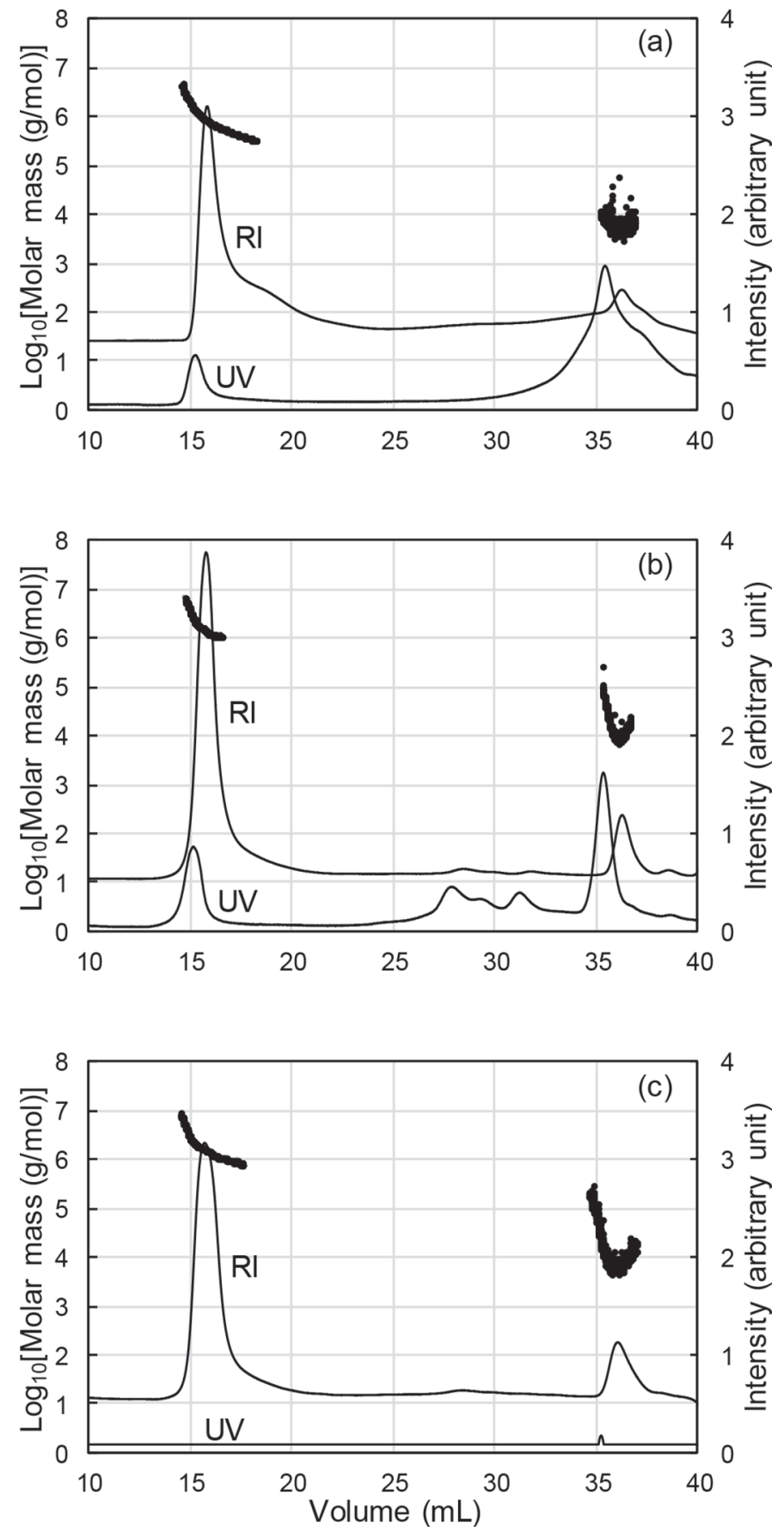

Figure 3. Size exclusion chromatography refractive index (RI) and UV elution profiles of soybean pectin overlaid with calculated molar masses (solid circles). Extraction was performed at $121^{\circ} \mathrm{C}$ (a) or at room temperature $(\mathrm{b}, \mathrm{c})$ followed by alkaline treatment $(\mathrm{c})$. 
In AMD, soybean pectin is expected to bind to $\mathrm{CN}$ through electrostatic interactions between negatively charged galacturonic acid groups and positively charged patches on $\mathrm{CN}$ micelles. Casein micelles are then stabilized by electrostatic repulsions and steric hindrance provided by loops and tails that pectin backbones form as well as neutral sugar side chains of pectin. The present results show that SPH had a slightly higher galacturonic acid content than SPRT and was more negatively charged at $\mathrm{pH} 3$ to 5 . Therefore, $\mathrm{SPH}$ is considered to have a better binding ability to $\mathrm{CN}$ micelles than SPRT if used as a stabilizer in AMD. However, SPRT had a higher molar mass as well as a larger size than $\mathrm{SPH}$, suggesting its greater steric effects on $\mathrm{CN}-$ $\mathrm{CN}$ interactions.

\section{Concentration Effects on AMD Stability}

Figures 4 and 5 show particle size distributions in AMD samples prepared using 0.2 to $0.8 \% \mathrm{SPH}$ and SPRT, respectively. At $0.2 \%$, monomodal distributions were observed in both SPH- and SPRT-stabilized $\mathrm{AMD}$, and they had similar median values $(1,230 \pm$ $40 \mathrm{~nm}$ for SPH; $1,220 \pm 70 \mathrm{~nm}$ for SPRT). At $0.4 \%$, second peaks with median values of $188 \pm 4 \mathrm{~nm}$ for SPH and $242 \pm 18 \mathrm{~nm}$ for SPRT appeared at lower diameters. These peaks in the diameter range from approximately 100 to $500 \mathrm{~nm}$ were observed consistently in AMD samples prepared using 0.4 to $0.8 \% \mathrm{SPH}$ or SPRT, indicating that excess soybean pectin molecules that were not bound to milk proteins existed at pectin concentrations $\geq 0.4 \%$. The larger diameter ranges of these second peaks compared with those measured in the absence of milk proteins (Figure 1) may be attributed to self-aggregation of excess pectin molecules in AMD due to reduced intermolecular electrostatic repulsions. In AMD containing 0.6 and $0.8 \%$ SPRT (Figure 5), third peaks were observed around $5.5 \mu \mathrm{m}$. These large particles were most likely to represent large protein aggregates.

Zeta potential is considered to be an indicator of electrostatic interactions between milk protein particles in AMD. Milk protein solutions immediately before acidification showed a zeta potential value of $-9.7 \pm$ $0.1 \mathrm{mV}$, indicating that they were stable systems. After acidification, the zeta potential of AMD increased to $+1.9 \pm 0.7 \mathrm{mV}$ due to a net positive charge of $\mathrm{CN}$ at $\mathrm{pH}$ less than the isoelectric point. This value was similar to a value of $+1 \mathrm{mV}$ reported by Sejersen et al. (2007). In contrast, AMD samples prepared using soybean pectin showed negative zeta potential values, suggesting the occurrence of electrostatic binding of negatively charged pectin molecules to milk proteins (Figure 6). The AMD samples prepared using SPH were more negatively charged than those prepared using SPRT at all examined concentrations except for $0.6 \%(P=0.21)$. These results were consistent with the results from zeta potential measurements of aqueous solutions of soybean pectin in the absence of milk proteins, where $\mathrm{SPH}$ was shown to be more negatively charged than SPRT at $\mathrm{pH} 4$ (Figure 2).

Other factors that contribute to the stabilization of AMD by polysaccharide stabilizers are bridging and depletion effects. The bridging effect is a primary concern when the polysaccharide concentration is too low (e.g., $1 \mathrm{mg} / \mathrm{kg}$ ) to provide the full coverage of protein surfaces (Dickinson et al., 1989; van Oss et al., 1990). The pectin molecule has multiple negatively charged groups that can bind to positively charged patches of protein along its molecular chain. Bridging occurs if a single pectin molecule binds to multiple protein particles and is observed as an increase in particle
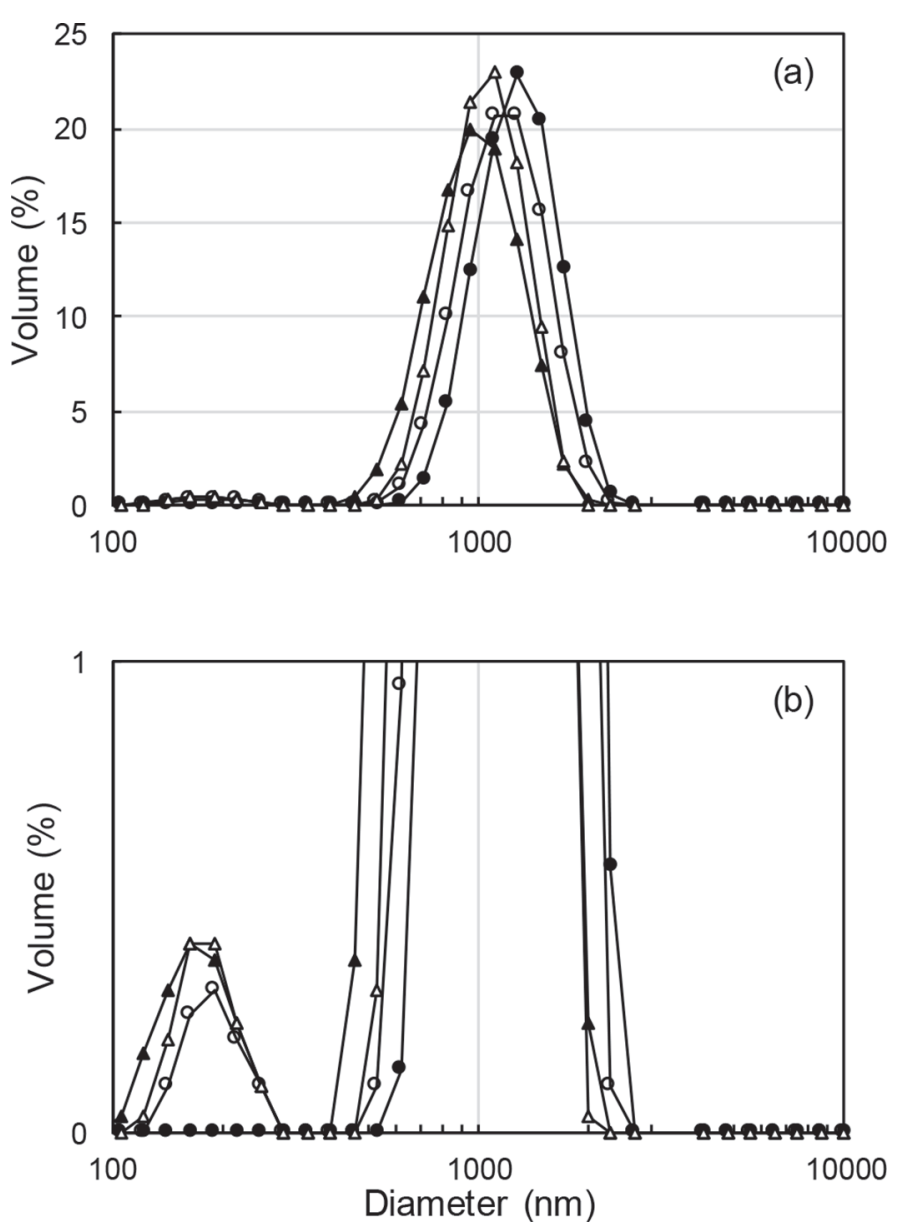

Figure 4. (a) Volume-based particle size distributions in acidified milk samples ( $\mathrm{pH} 4$ ) containing $0.2 \%$ (solid circles), $0.4 \%$ (open circles), $0.6 \%$ (solid triangles), and $0.8 \%$ (open triangles) soybean pectin extracted at $121^{\circ} \mathrm{C}$. (b) The same data as in panel a plotted on a different $y$-axis scale. 

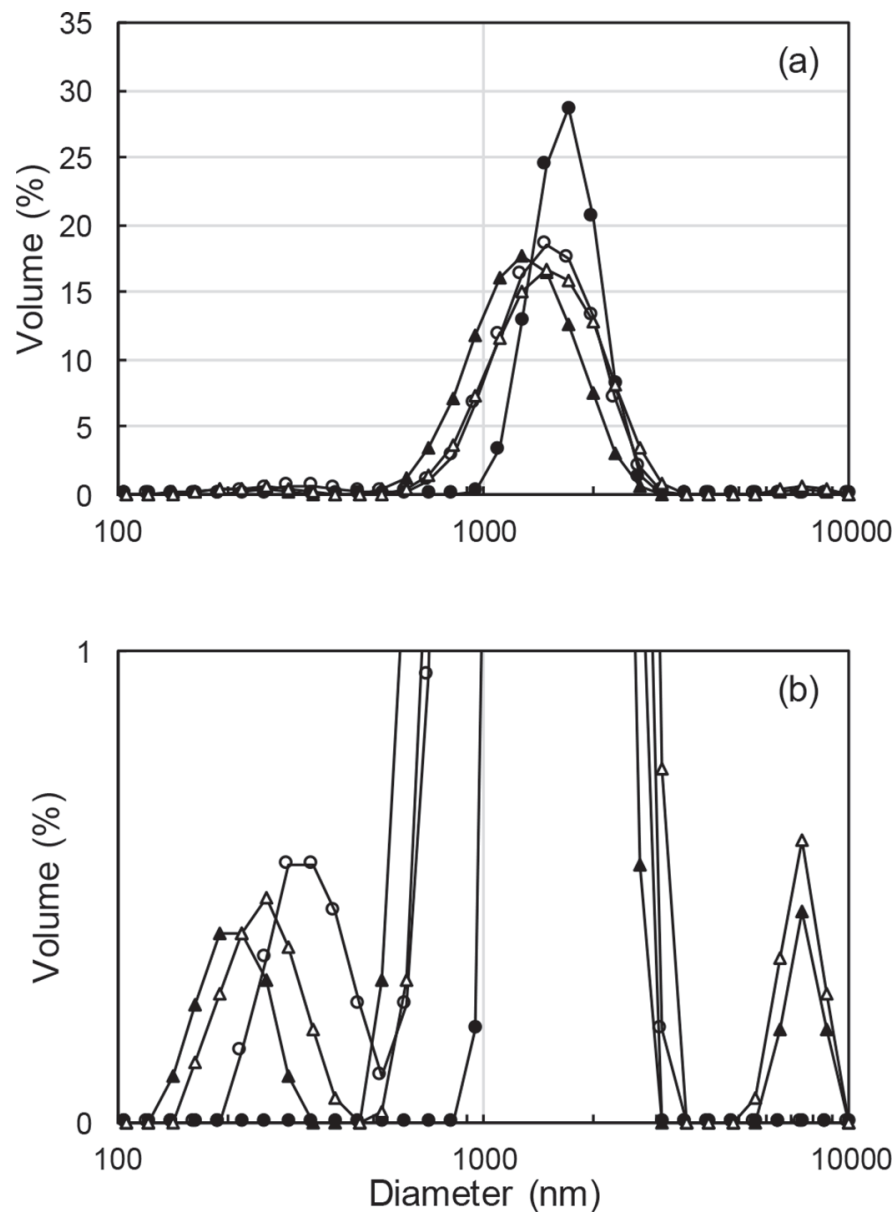

Figure 5. (a) Volume-based particle size distributions of acidified milk samples ( $\mathrm{pH} 4$ ) containing $0.2 \%$ (solid circles), $0.4 \%$ (open circles), $0.6 \%$ (solid triangles), and $0.8 \%$ (open triangles) soybean pectin extracted at room temperature. (b) The same data as in panel a plotted on a different $y$-axis scale.

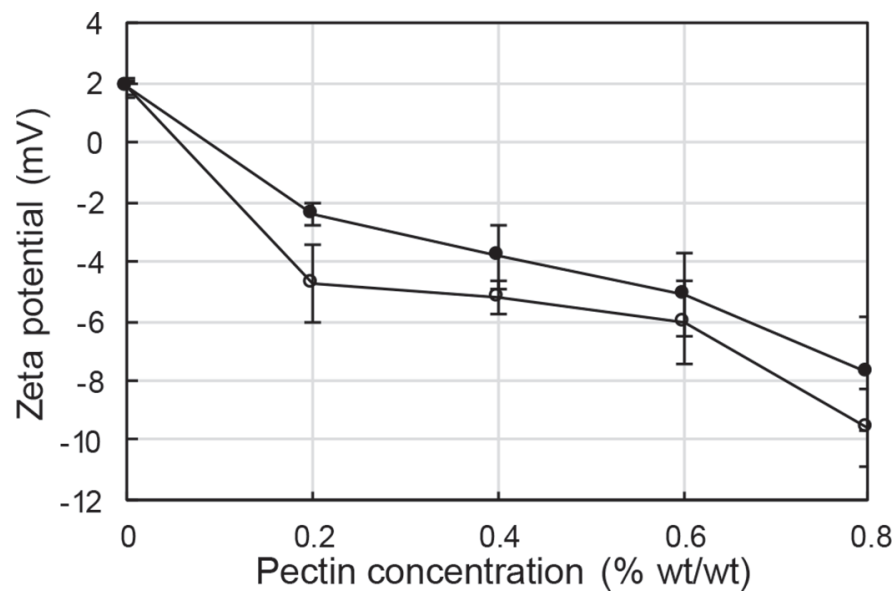

Figure 6. Zeta potentials of acidified milk samples ( $\mathrm{pH} 4$ ) containing soybean pectin extracted at $121^{\circ} \mathrm{C}$ (open circles) or at room temperature (solid circles). Error bars indicate standard deviation. sizes (Syrbe et al., 1998; Tuinier et al., 2002; Laurent and Boulenguer, 2003). Bridging-induced aggregation has been reported to occur in AMD prepared using high-methoxyl pectin (Syrbe et al., 1998) but not in AMD prepared using SSPS, most likely because SSPS molecules are too compact to bridge multiple protein particles. In contrast, the depletion effect is typically observed when the polysaccharide concentration is so high that protein surfaces are fully covered and excess polysaccharide molecules exist (van Oss et al., 1990). Such excess polysaccharide molecules that are not bound to protein increase the osmotic pressure of the surrounding solution. If 2 protein particles in Brownian motion come close and the separation distance between them becomes less than the size of the polysaccharide molecule, polysaccharide molecules are excluded from the region between the adjacent protein particle surfaces, leading to a reduction in the osmotic pressure of the region. The higher osmotic pressure of the surrounding solution then drives water from the interparticle region into the bulk, clumping the protein particles together (De Kruif and Tuinier, 2001).

The large particles observed in AMD samples containing 0.6 and $0.8 \%$ SPRT (Figure 5) were most likely to have resulted from depletion-induced aggregation. As mentioned already, the presence of the second peaks around 100 to $500 \mathrm{~nm}$ is an indication that protein surfaces are fully covered at $0.4 \%$. Therefore, enhanced protein aggregation at higher pectin concentrations is unlikely to be attributable to the bridging effect and rather is likely due to the depletion effect induced by excess pectin molecules residing in the bulk solution. As shown in Figure 4, AMD prepared using SPH did not show any large particles around $5 \mu \mathrm{m}$ despite the emergence of the second peaks around 100 to $500 \mathrm{~nm}$, indicating the presence of excess pectin molecules at pectin concentrations $\geq 0.4 \%$. These results can be attributed to the lower molar mass of SPH than of SPRT because higher molecular weight polymers are expected to induce more enhanced depletion effects (Biggs et al., 2000; Milling and Kendall, 2000).

\section{pH Effects on AMD Stability}

At $\mathrm{pH} 4,0.2 \%$ soybean pectin was considered to be sufficient to stabilize AMD containing 8.5\% milk solids without generating excess pectin molecules unbound to proteins (Figures 4 and 5). Therefore, effects of $\mathrm{pH}$ on the stability of AMD were investigated at a pectin concentration of $0.2 \%$. Monomodal distributions were observed in AMD prepared using SPH at pH 3.2 (Figure 7) and those prepared using SPRT at 3.6 (Figure 8). Peaks representing excess pectin molecules that were unbound to proteins emerged in AMD prepared 

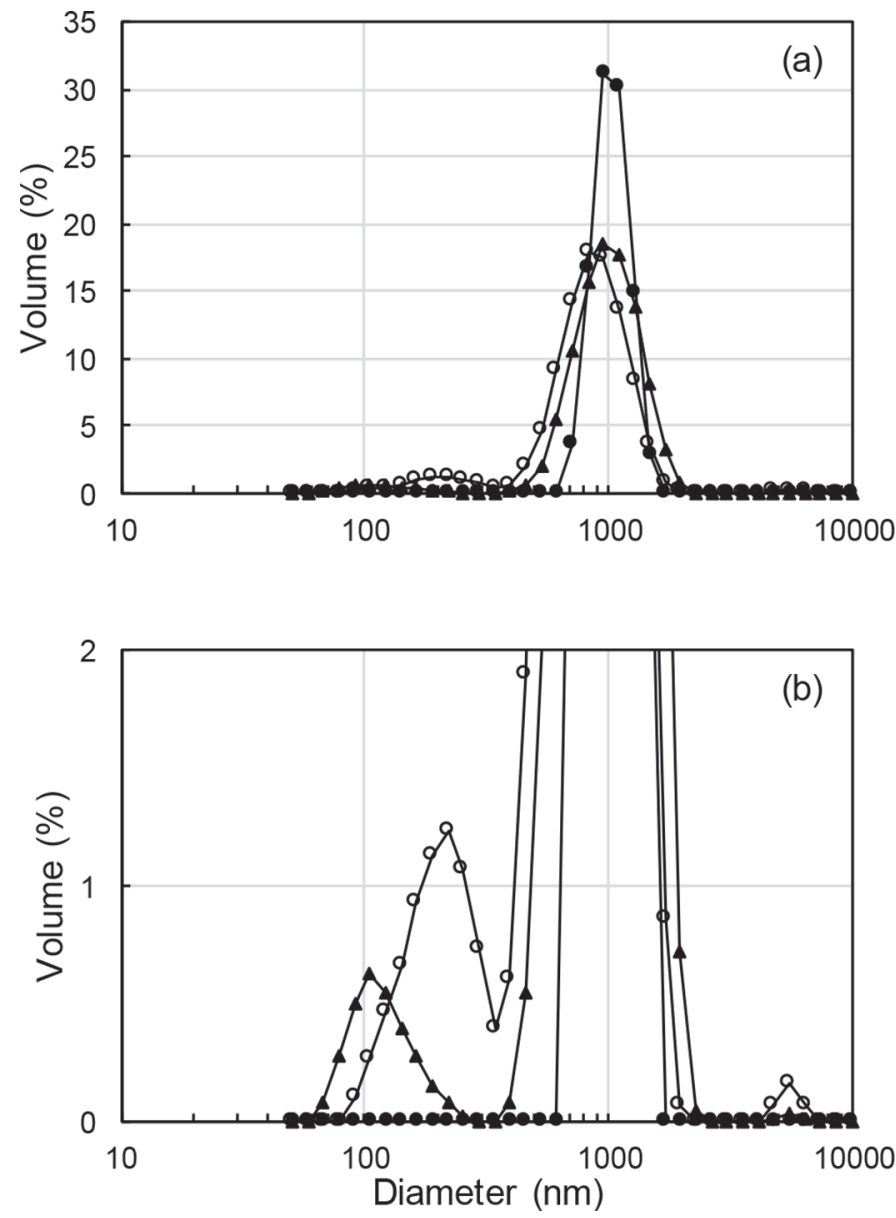

Figure 7. (a) Volume-based particle size distributions of acidified milk samples containing $0.2 \%$ soybean pectin extracted at $121^{\circ} \mathrm{C}$ and adjusted to $\mathrm{pH} 3.2$ (solid circles), 3.4 (open circles), and 3.6 (solid triangles). (b) The same data as in panel a plotted on a different $y$ axis scale.

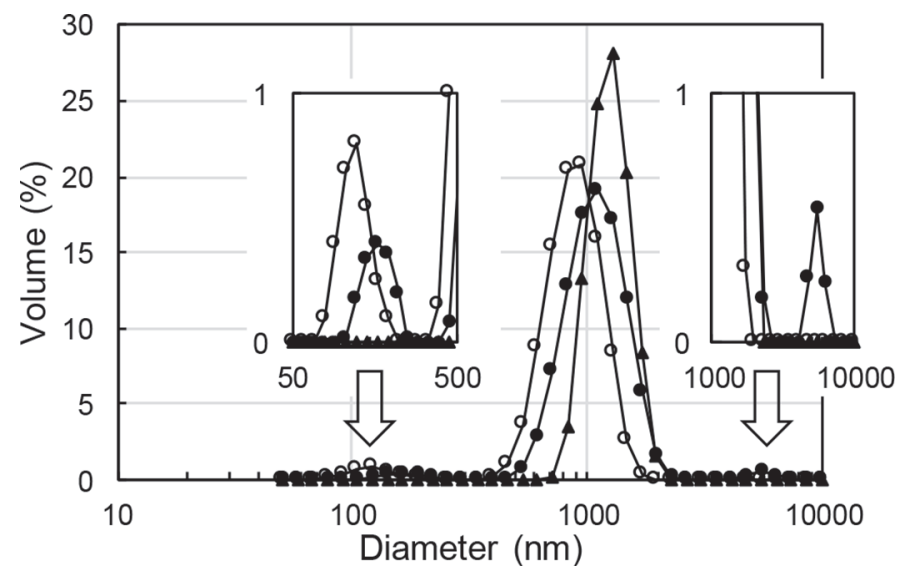

Figure 8. Volume-based particle size distributions of acidified milk samples containing $0.2 \%$ soybean pectin extracted at room temperature and adjusted to $\mathrm{pH} 3.2$ (solid circles), 3.4 (open circles), and 3.6 (solid triangles). using SPH at pH 3.4 and 3.6 (Figure 7) and those prepared using SPRT at pH 3.2 and 3.4 (Figure 8) in the diameter range around $100 \mathrm{~nm}$. The presence of large protein aggregates, diameters of which were around 5 $\mu \mathrm{m}$, was detected in AMD prepared using $\mathrm{SPH}$ at $\mathrm{pH}$ 3.4 (Figure 7) and those prepared using SPRT at $\mathrm{pH}$ 3.2 (Figure 8). These results suggest that the optimal $\mathrm{pH}$ for the stability of AMD is 3.2 for $\mathrm{SPH}$ and 3.6 for SPRT in this $\mathrm{pH}$ range. As $\mathrm{pH}$ decreases from 4.0 to 3.2 , CN proteins become more net-positively charged, whereas galacturonic acid groups become less negatively charged. The optimal $\mathrm{pH}$ for stabilizing abilities of soybean pectin appears to be determined by an intricate interplay between charged states of pectin and protein molecules.

\section{CONCLUSIONS}

The present study demonstrated that the structure and functionality of pectin can be differentiated by manipulating extraction conditions. The soybean pectin extracted using the conventional method at elevated temperatures was characterized by a lower molar mass and a lower optimal $\mathrm{pH}$ for the stabilization of AMD. The soybean pectin extracted at room temperature better preserved native molecular characteristics, evident by an increased molar mass, and was suggested to contain protein moieties covalently linked to pectin moieties via the $O$-linkage. The protein moiety was suggested to play an important role in the determination of charged states of the overall molecule and hence protein stabilizing abilities. The soybean pectin extracted at room temperature was capable of stabilizing AMD containing $8.5 \%$ milk solids at $\mathrm{pH} 4$ at concentrations as low as $0.2 \%$, whereas increasing pectin concentration increased the number of pectin molecules that were not bound to proteins as well as the likelihood of causing depletion-induced protein aggregation.

\section{ACKNOWLEDGMENTS}

This work was supported by the USDA National Institute of Food and Agriculture (Washington, DC; Hatch project no. 1003055).

\section{REFERENCES}

Akiyama, Y., S. Eda, and K. Kato. 1984. Gum arabic is a kind of arabinogalactan-protein. Agric. Biol. Chem. 48:235-237.

Biggs, S., J. L. Burns, Y. Yan, G. J. Jameson, and P. Jenkins. 2000. Molecular weight dependence of the depletion interaction between silica surfaces in solutions of sodium poly(styrene sulfonate). Langmuir 16:9242-9248.

Caffall, K. H., and D. Mohnen. 2009. The structure, function, and biosynthesis of plant cell wall pectic polysaccharides. Carbohydr. Res. 344:1879-1900. 
Chivero, P., S. Gohtani, S. Ikeda, and A. Nakamura. 2014. The structure of soy soluble polysaccharide in aqueous solution. Food $\mathrm{Hy}-$ drocoll. 35:279-286.

Corbo, M. R., A. Bevilacqua, L. Petruzzi, F. P. Casanova, and M. Sinigaglia. 2014. Functional beverages: The emerging side of functional foods. Compr. Rev. Food Sci. Food Saf. 13:1192-1206.

Dalgleish, D. G. 1998. Casein micelles as colloids: Surface structures and stabilities. J. Dairy Sci. 81:3013-3018.

De Kruif, C. G., and R. Tuinier. 2001. Polysaccharide protein interactions. Food Hydrocoll. 15:555-563.

Dickinson, E., D. J. Elverson, and B. S. Murray. 1989. On the filmforming and emulsion-stabilizing properties of gum arabic: Dilution and flocculation aspects. Food Hydrocoll. 3:101-104.

Faravash, R. S., and F. Z. Ashtiani. 2007. The effect of pH, ethanol volume and acid washing time on the yield of pectin extraction from peach pomace. Int. J. Food Sci. Technol. 42:1177-1187.

Ikeda, S., T. Funami, and G. Zhang. 2005. Visualizing surface active hydrocolloids by atomic force microscopy. Carbohydr. Polym. 62:192-196.

Jensen, S., C. Rolin, and R. Ipsen. 2010. Stabilisation of acidified skimmed milk with HM pectin. Food Hydrocoll. 24:291-299.

Kirby, A. R., A. J. MacDougall, and V. J. Morris. 2006. Sugar beet pectin-protein complexes. Food Biophys. 1:51-56.

Laurent, M. A., and P. Boulenguer. 2003. Stabilization mechanism of acid dairy drinks (ADD) induced by pectin. Food Hydrocoll. $17: 445-454$.

Liu, J., A. Nakamura, and M. Corredig. 2006. Addition of pectin and soy soluble polysaccharide affects the particle size distribution of casein suspensions prepared from acidified skim milk. J. Agric. Food Chem. 54:6241-6246.

Matsumura, Y., M. Egami, C. Satake, Y. Maeda, T. Takahashi, A. Nakamura, and T. Mori. 2003. Inhibitory effects of peptide-bound polysaccharides on lipid oxidation in emulsions. Food Chem. 83:107-109.

Milling, A. J., and K. Kendall. 2000. Depletion, adsorption, and structuring of sodium poly(acrylate) at the water-silica interface. 1. An atomic force microscopy force study. Langmuir 16:5106-5115.

Nakamura, A., N. Fujii, J. Tobe, N. Adachi, and M. Hirotsuka. 2012. Characterization and functional properties of soybean high-molecular-mass polysaccharide complex. Food Hydrocoll. 29:75-84.

Nakamura, A., H. Furuta, M. Kato, H. Maeda, and Y. Nagamatsu. 2003. Effect of soybean soluble polysaccharides on the stability of milk protein under acidic conditions. Food Hydrocoll. 17:333-343.

Nakamura, A., H. Furuta, H. Maeda, Y. Nagamatsu, and A. Yoshimoto. 2001. Analysis of structural components and molecular construction of soybean soluble polysaccharides by stepwise enzymatic degradation. Biosci. Biotechnol. Biochem. 65:2249-2258.

Nakamura, A., H. Furuta, H. Maeda, T. Takao, and Y. Nagamatsu. 2002. Structural studies by stepwise enzymatic degradation of the main backbone of soybean soluble polysaccharides consisting of galacturonan and rhamnogalacturonan. Biosci. Biotechnol. Biochem. 66:1301-1313.

Nakamura, A., H. Maeda, and M. Corredig. 2006a. Emulsifying properties of enzyme-digested soybean soluble polysaccharide. Food Hydrocoll. 20:1029-1038.
Nakamura, A., T. Takahashi, R. Yoshida, H. Maeda, and M. Corredig. 2004a. Emulsifying properties of soybean soluble polysaccharide. Food Hydrocoll. 18:795-803.

Nakamura, A., R. Yoshida, H. Maeda, and M. Corredig. 2006b. The stabilizing behavior of soybean soluble polysaccharide and pectin in acidified milk beverages. Int. Dairy J. 16:361-369.

Nakamura, A., R. Yoshida, H. Maeda, H. Furuta, and M. Corredig. 2004b. Study of the role of the carbohydrate and protein moieties of soy soluble polysaccharides in their emulsifying properties. J. Agric. Food Chem. 52:5506-5512.

Nobuhara, T., K. Matsumiya, Y. Nambu, A. Nakamura, N. Fujii, and Y. Matsumura. 2014. Stabilization of milk protein dispersion by soybean soluble polysaccharide under acidic pH conditions. Food Hydrocoll. 34:39-45.

Ntazinda, A., M. J. Cheserek, L. Sheng, J. Meng, and R. Lu. 2014. Combination effect of sodium carboxymethyl cellulose and soybean soluble polysaccharides on stability of acidified skimmed milk drinks. Dairy Sci. Technol. 94:283-295.

Patel, T., J. Bruce, A. Merry, C. Bigge, M. Wormald, A. Jaques, and R. Parekh. 1993. Use of hydrazine to release in intact and unreduced form both $\mathrm{N}$ - and O-linked oligosaccharides from glycoproteins. Biochemistry 32:679-693.

Pereyra, R., K. A. Schmidt, and L. Wicker. 1997. Interaction and stabilization of acidified casein dispersions with low and high methoxyl pectins. J. Agric. Food Chem. 45:3448-3451.

Philippe, M., Y. Le Graet, and F. Gaucheron. 2005. The effects of different cations on the physicochemical characteristics of casein micelles. Food Chem. 90:673-683.

Sejersen, M. T., T. Salomonsen, R. Ipsen, R. Clark, C. Rolin, and S. B. Engelsen. 2007. Zeta potential of pectin-stabilised casein aggregates in acidified milk drinks. Int. Dairy J. 17:302-307.

Sila, D. N., S. Van Buggenhout, T. Duvetter, I. Fraeye, A. De Roeck, A. Van Loey, and M. Hendrickx. 2009. Pectin in processed fruits and vegetables: Part II-Structure-function relationships. Compr. Rev. Food Sci. Food Saf. 8:86-104.

Syrbe, A., W. J. Bauer, and H. Klostermeyer. 1998. Polymer science concepts in dairy systems-An overview of milk protein and food hydrocolloid interaction. Int. Dairy J. 8:179-193.

Taylor, K. A. 1993. A colorimetric method for the quantitation of galacturonic acid. Appl. Biochem. Biotechnol. 43:51-54.

Tres, M. V., J. C. Racoski, M. Di Luccio, J. V. Oliveira, H. Treichel, D. de Oliveira, and M. A. Mazutti. 2014. Separation of soybean oil/n-hexane and soybean oil/n-butane mixtures using ceramic membranes. Food Res. Int. 63:33-41.

Tromp, R. H. C. G. De Kruif, M. Van Eijk, and C. Rolin. 2004. On the mechanism of stabilization of acidified milk drinks by pectin. Food Hydrocoll. 18:565-572.

Tuinier, R., C. Rohlin, and C. G. De Kruif. 2002. Electrosorption of pectin onto casein micelles. Biomacromolecules 3:632-638.

van Oss, C. J., K. Arnold, and W. T. Coakley. 1990. Depletion flocculation and depletion stabilization of erythrocytes. Cell Biophys. 17:1-10.

Zhu, D., S. Damodaran, and J. A. Lucey. 2008. Formation of whey protein isolate (WPI)-dextran conjugates in aqueous solutions. J. Agric. Food Chem. 56:7113-7118. 